\title{
Desafios para os professores de inglês de programas bilíngues nas escolas particulares de fortaleza
}

\author{
Andréa Regina Silva Santa Ana \\ Pâmela Freitas Pereira Toassi ${ }^{2}$
}

\begin{abstract}
Resumo: Neste estudo, discutimos sobre a prática dos professores de programas bilíngues nas escolas particulares de Fortaleza, uma modalidade de ensino recente e sem abrangência legislativa no Brasil. O objetivo deste estudo foi entender se as mudanças identificadas no cenário de ensino de língua inglesa nas escolas particulares de Fortaleza se traduzem como vantajosas para os professores, para tanto, ancorados na literatura sobre bilinguismo e multilinguismo e formação de professores, buscamos: a) Investigar a percepção dos professores sobre a chegada dos programas bilíngues nas escolas particulares de Fortaleza; b) Identificar os saberes que professores devem mobilizar para realizar seu trabalho e, c) Avaliar se os professores percebem os programas bilíngues como vantajosos para eles. A fim de esboçar um perfil desses docentes e coletar dados para nosso estudo, aplicamos um questionário a 29 professores voluntários. A análise das respostas obtidas mostrou que os educadores bilíngues estão sendo valorizados no âmbito escolar fortalezense, contudo, ainda há carência em formação, principalmente, continuada. O presente estudo espera trazer uma contribuição para as investigações sobre esta modalidade de ensino de inglês recém-chegada, porém, significativa.
\end{abstract}

Palavras-chave: programas bilíngues, formação de professores, bilinguismo.

\section{Introdução}

Identificamos a partir de campanhas de marketing (outdoors, rádio e televisão), vinculadas por escolas privadas da cidade de Fortaleza, oferta de programas bilíngues

1 Especialista em ensino e aprendizagem de linguas estrangeiras (Universidade da Amazônia) e em Linguística Aplicada e Ensino de Linguas Estrangeiras (CELEST/UFC). Mestranda do Programa de Pós-graduação em Linguística Aplicada da Universidade Estadual do Ceará-POSLA. andreasantaana22@gmail.com.

2 Universidade Federal do Ceará. Doutora em Estudos da Linguagem (PPGI/UFSC). Professora do Departamento de Estudos da Língua Inglesa, suas Literaturas e Tradução (DELILT/UFC) e do Programa de Pós-Graduação em Estudos da Tradução (POET/UFC). pamelatoassi.ufc@gmail.com

Gláuks: Revista de Letras e Artes-jan/jun. 2020 -Vol. 20, $N^{o} 1$ 


\section{GLÁUKS}

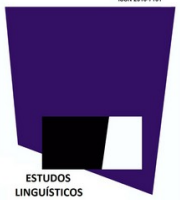

inglês/português para alunos da educação básica. Esses programas propõem aulas de língua inglesa dentro da carga horária diária, alinhadas com propostas pedagógicas contemporâneas e com a concepção da linguagem como processo de interação (BAKTHIN, 2014). O amadurecimento das propostas de ensino de língua inglesa evidencia um desenvolvimento na educação para comunidades mais globalizadas e fronteiras são derrubadas (ROJO, 2013) e a troca de conhecimento ocorre.

Estudos mais recentes reforçam estas premissas (MEGALE, 2005; 2014; MEGALE; LIBERALI, 2017), destacando o aumento da demanda de escolas e trazendo ao debate a formação de professores para o ensino de inglês em programas bilíngues como o grande desafio, uma vez que a legislação brasileira que trata da educação não contempla a modalidade. No cenário atual, a formação para o ensino de línguas na educação básica se dá em nível de graduação - curso de Letras, para atendimento ao ensino fundamental anos finais e ensino médio. Já no caso da educação infantil e ensino fundamental anos iniciais, a formação específica para atendimento a esse público é a Pedagogia.

A partir dos aspectos supracitados, percebemos que a sala de aula se modifica e essas mudanças projetam um novo perfil de professor: um profissional versátil, capaz de combinar diferentes abordagens e fomentar projetos transdisciplinares. O referido cenário de ensino de inglês influencia a carreira dos professores questionando aspectos de sua formação e expectativas das escolas, dos pais, dos alunos e dos próprios professores quanto à sua atividade profissional.

Atualmente, os programas bilíngues prestigiam a língua inglesa no currículo, estando assim de acordo com os documentos oficiais que apontam o estudo da língua inglesa como motivador aos estudantes, não apenas para a aquisição de conhecimentos, mas também para a continuidade nos estudos (BRASIL, 2018). O objetivo das escolas particulares que optam por implementar programas bilíngues à sua grade curricular é melhorar o ensino do idioma, além de atender a uma demanda das famílias. Portanto, a chegada dos programas bilíngues às escolas aponta para a necessidade de se estudar sobre os conceitos de educação bilíngue, bilinguismo e multilinguismo. A contento, estamos formando crianças e jovens bilíngues, 
devemos nos apropriar desses conceitos para compreender melhor o processo de aprendizagem desses alunos.

Estudantes dos programas bilíngues nas escolas de Fortaleza atingirão necessariamente algum nível de proficiência nas quatro habilidades essenciais ao processo de comunicação. Segundo Marcelino (2009), podemos identificá-los como bilíngues consecutivos, já que, em suas aulas, a língua inglesa não é o instrumento de obtenção de conhecimento, mas o objeto de estudo, com a observação de que essa instrução acontece nas escolas regulares e não nos cursos de idiomas. Além disso, observamos que os exames internacionais de proficiência se destacam como balizadores da qualidade de ensino, para crianças a partir dos 7 (sete) anos nas escolas de Fortaleza. Nesse contexto educacional, o material didático se volta para projetos interdisciplinares, investigação de fenômenos e abordagem CLIL (Content and Language Integrated Learning).

Sendo assim, questionamos sobre a formação dos professores de inglês dos programas bilíngues, sobretudo sobre os saberes que devem mobilizar para realizar seu trabalho. Não podemos deixar de pontuar que os professores em questão, muito provavelmente, aprenderam inglês com outras abordagens, enquanto alunos passaram por outras experiências didáticometodológicas. Os cursos de idiomas são, em grande parte, embasados na abordagem comunicativa e com propostas para grupos pouco numerosos e, na escola básica, grande parte desses profissionais vivenciaram métodos mais tradicionais que envolvem tradução ou inglês instrumental. Portanto, os registros e referências dos professores e, consequentemente suas crenças enquanto estudantes de língua estrangeira, podem não se encaixar na atual sala de aula onde atuam como professores.

A dimensão destas mudanças no cenário profissional configura-se como excelente campo para pesquisa; o professor, uma fonte fidedigna para compreender as mudanças, adaptações e expectativas que permeiam esse cenário. É importante salientar que esse é um estudo restrito às escolas particulares da cidade de Fortaleza, os programas bilíngues são recentes e no âmbito da pesquisa ainda há bastante a se explorar. Certamente há muita 
diversidade de programas e não temos a intenção de contemplar todos. Manteremos nosso foco no professor e em sua atividade profissional, e não na formação do aluno.

O objetivo deste estudo é entender se as mudanças identificadas no cenário de ensino de língua inglesa nas escolas particulares de Fortaleza se traduzem como vantajosas para os professores. Para isso identificamos, a partir de um questionário, o perfil profissional do professor, assim como aspectos de sua formação e sua prática nos programas bilíngues. Buscamos realizar as análises a partir de teorias sobre ensino e aprendizagem de idiomas (ROJO, 2013; ALMEIDA FILHO, 2007; BARCELOS, 2011; MEGALE, 2014), educação bilíngue, bilinguismo e multilinguismo (MARCELINO, 2009; MEGALE, 2005; 2014; MEGALE; LIBERALI, 2017; GROSJEAN, 1982; CAVALCANTI, 1999; GARCIA, 2009; GARCIA; JOHNSON; SELTZER, 2017; MAHER, 2006) e do contexto educacional da cidade de Fortaleza.

Este artigo está organizado em seis seções, além dessa introdução, na segunda, explanamos sobre Bilinguismo e Multilinguismo no Ensino Básico do Brasil. Na terceira, são abordados os estudos sobre a Formação do Professor de Inglês no Brasil. Na quarta, apresentamos a Metodologia, subdividida em dois tópicos: contextualização do presente estudo e a descrição dos participantes. A quinta seção consiste na Análise e Discussão dos Resultados. Por último, a sexta seção contém as Considerações Finais.

\section{Bilinguismo e Multilinguismo no Ensino Básico no Brasil}

Qual a intenção de denominar um país com as dimensões e história do Brasil de "nação monolíngue" se sabemos que historicamente os ideais de língua padrão ou oficial carregam interesses ideológicos e políticos, que a língua portuguesa veio de fora, que temos raízes indígenas, africana e de imigrantes? $\mathrm{Na}$ verdade, o monolinguismo é um fenômeno quase impossível de ser identificado (GARCIA, 2009) e o mito do monolinguismo no Brasil, segundo Cavalcanti (1999, p.387) “é eficaz para apagar as minorias, isto é, as nações 


\section{GLÁUKS}

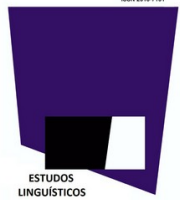

indígenas, as comunidades imigrantes e, por extensão, as maiorias tratadas como minorias, ou seja, as comunidades falantes de variedades desprestigiadas do português." A intenção foi e é, portanto, política. Perpetua-se, apesar da maturidade da nação, e a sala de aula é o local de onde poderá partir o questionamento, a indignação e a reconstrução do perfil sociolinguístico do Brasil.

Imigrantes, comunidade surda e indígenas são integrantes da grande variedade cultural e linguística do Brasil, no entanto, muitos brasileiros se consideram originários de uma nação monolíngue, pois, infelizmente, nossa história foi escrita de forma a apagar outras origens e outras variações linguísticas diferentes do português, a língua do colonizador. Esse fato nos coloca em posição de ignorar o bilinguismo e o multilinguismo ao nosso redor. Seguimos com alguns números para afirmar nossa variação cultural e linguística. No ano de 1500, havia algo em torno de 4 milhões de indígenas em terras brasileiras e mais de 1400 línguas (MAHER, 2006). Depois, com a intenção de colonizar ou em busca de oportunidades no país recém "descoberto", e devemos registrar que Maher não concorda com esse termo, quatro milhões de imigrantes de várias nacionalidades chegaram ao Brasil, ainda seis milhões de negros vindos da África - de diferentes etnias, por conseguinte, falando línguas diversas para trabalhos forçados.

Há uma riqueza de estudos sobre bilinguismo, muitos deles realizados na Europa e nos Estados Unidos, grande parte com foco na língua inglesa. No Brasil, testemunhamos um número crescente de pesquisadores da área da Linguística Aplicada desenvolvendo trabalhos sobre bilinguismo nas escolas bilíngues indígenas (CAVALCANTI,1999; MAHER, 2006), no ensino de libras, na educação bilíngue (MEGALE, 2014; MEGALE; LIBERALI, 2017) e no ensino de língua adicional.

O professor de inglês, hoje trabalhando em escolas com programas bilíngues, precisa de uma formação que traga a história da língua de forma abrangente, de sua língua materna, do que é uma língua franca, de prestígio (MEGALE; LIBERALI, 2017) ou segunda língua ou ainda língua estrangeira, para que esse profissional não assuma uma posição ingênua sobre o poder que uma língua detém e perpetue mitos como o do monolinguismo. Infelizmente, 
brasileiros que frequentaram a escola pouco conhecem sobre o perfil sociolinguístico do Brasil e isso nos torna uma nação cega aos preconceitos linguísticos e à nossa própria identidade. Observamos na citação a seguir o perfil sociolinguístico de nosso país colocado por Maher em um texto do material elaborado para formação de professores indígenas, da Coleção Educação para Todos, em uma parceria com MEC e UNESCO.

E no Brasil? Como é o perfil sociolinguístico de nosso país? Quantas línguas são faladas aqui? Pouquíssimos brasileiros sabem que no Brasil existem 180 línguas indígenas. Há, além disso, 30 línguas de imigrantes: há crianças brasileiras que, antes de entrarem na escola, falam exclusivamente a língua do país de origem de seus pais. Temos também, no país, 2 línguas de sinais: temos a língua de sinais brasileira (LIBRAS) e a língua de sinais dos UrubuKaapor. E, evidentemente, há a língua oficial do país: a língua portuguesa. Feitas as contas, são utilizadas hoje, por cidadãos brasileiros natos, pelo menos 213 línguas como línguas maternas. (MAHER, 2006, p. 29,30).

Essa discussão é de singular importância para a formação, não apenas de professores da área de linguagem, mas de todos os professores, de todas as escolas brasileiras, especialmente àqueles que formam alunos bilíngues. E nos referimos às escolas de ensino bilíngue de libras, às escolas indígenas e de fronteira e às que tem programas bilíngues com línguas de prestígio. Esses professores devem compreender o que esse aprendizado significa para seus alunos a longo prazo e o que essa língua diz de sua identidade.

Nesse contexto, é importante discutirmos o conceito de bilinguismo e os elementos que devem fazer parte da formação do professor que forma alunos bilíngues. O intenso crescimento de programas bilíngues em Fortaleza aparece com a missão de educar para a realidade multilíngue e multicultural do século XXI. Em alguns estados do Brasil, principalmente São Paulo, há alguns anos, assistimos a expansão de uma Educação bilíngue de elite.

Trazemos o questionamento sobre a trajetória de aprendizagem desses estudantes para atingir um certo nível de proficiência bilíngue, pois queremos discorrer sobre o que o professor desse aluno deve saber para facilitar essa trajetória. É importante que esse mestre saiba dos diferentes estudos e das diferentes definições de bilinguismo, pois há diversas

Gláuks: Revista de Letras e Artes-jan/jun. 2020 - Vol. 20, $N^{o} 1$ 


\section{GLÁUKS}

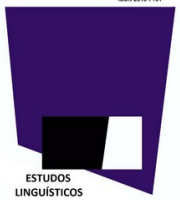

perspectivas a serem estudadas para que os professores possam adaptar-se à realidade de seus alunos.

Para Bloomfield (1935), que define uma pessoa bilíngue como aquela que cresce falando duas línguas; a experiência bilíngue ou multilíngue, viria da infância. Podemos dizer que essa é a definição mais difundida entre os professores brasileiros que revelam a crença de não se reconhecerem como pessoas bilíngues (MARCELINO, 2009). Em uma definição objetiva, Grosjean (1982) aponta a fluência em duas línguas como a característica principal de uma pessoa bilíngue. Grosjean cita que há admiração pela sociedade em geral por essas pessoas, talvez por ser uma habilidade difícil de ser alcançada cognitiva e psicologicamente, sentir-se membro de duas comunidades de fala diferentes. Outro estudioso, Thiery (1978) também coloca a pessoa bilíngue como membro de duas diferentes comunidades linguísticas, uma visão que acrescenta a cultura e a parte social da língua. Grosjean e Thiery utilizam a expressão "true bilingual” em suas definições, o bilíngue real ou verdadeiro em tradução livre.

Alguns autores pensam no bilinguismo em um continuum, como Valdés e Figueroa (1994); assim os sujeitos bilíngues estão em diferentes pontos desse continuum. Deve-se analisar não só a competência do indivíduo bilíngue, mas também outras dimensões de igual importância como organização cognitiva, idade de aquisição da língua adicional, presença ou não de indivíduos falantes da língua adicional no ambiente em questão, status das línguas envolvidas e identidade cultural. Assim como motivação e interesse, esforço e engajamento, incentivo da família e dos amigos.

Após discorrer sobre o bilinguismo e definir como podemos compreender as diferentes formas de se tornar um sujeito bilíngue consideramos importante lançar luz, na próxima seção, sobre a formação do professor que trabalha em programas bilíngues.

\section{A Formação do Professor de Inglês no Brasil}


Nas escolas particulares brasileiras é cada vez maior o interesse dos pais pela educação bilíngue $^{3}$, resguardadas as especificidades do termo, especialmente nos anos iniciais da educação básica, de forma especial português-inglês. Os pais com maior poder aquisitivo têm optado por escolas bi/multilíngues, seja por motivos de formação para o trabalho, de viagens ou mesmo de ampliação cultural. Temos observado que as escolas regulares absorvem essa nova demanda de ensino de inglês com mais qualidade, o que, mesmo que não se integre a uma distinção de educação bilíngue nos aspectos pedagógicos, cognitivos e linguísticos, tem proporcionado às escolas básicas uma certa vantagem frente aos centros de ensino de língua estrangeira (cursos de idioma) que, por décadas, representaram o local ideal para se aprender língua estrangeira no Brasil (BARCELOS, 2011, p. 149).

No tocante à legislação brasileira, não há regulamentação específica para essa modalidade de ensino, educação bilíngue português/inglês, até essa data, apesar das discussões em pauta, o que dá margem para que muitos professores sem formação adequada atuem em salas de aula bilíngues. Identificamos dois aspectos evidenciados nesse contexto, o primeiro é a carência de cursos para qualificação em educação bilíngue no país; e o segundo, a urgência da rede privada de ensino em atender a grande demanda, negligenciando um processo de formação contínua (em serviço) para estes profissionais.

Ainda sobre a legislação, acrescentamos que a Base Nacional Comum Curricular, vigente a partir de 2020 para escolas públicas e privadas, é o documento oficial norteador das políticas educacionais públicas e prescreve o ensino de língua inglesa a partir do $6^{\circ}$ ano do ensino fundamental (BRASIL, 2018). Há, por tanto, carência de normatizações de ensino de língua inglesa para a educação infantil e anos iniciais do ensino fundamental. Em relação à formação de professores para lecionar na educação infantil e ensino fundamental no Brasil, a Lei 9.394/1996, Lei de Diretrizes e Bases da Educação Nacional (LDB), afirma que essa "farse-á em nível superior, em curso de licenciatura, de graduação plena, em universidades e institutos superiores de educação" (BRASIL, 1998). A Lei determina, portanto, que a formação mínima para o professor seja a graduação. Uma vez que os cursos de graduação

3 Educação bilíngue pressupõe conceitos distintos em países e contextos diferenciados em função: de questões étnicas, dos próprios educadores e legisladores e de fatores sócio-políticos. (MEGALE, 2005, p.7) 
parecem ignorar a crescente demanda por professores que precisam ser capacitados para atuar em escolas bilíngues e em programas bilíngues - guardadas as diferenças entre os dois quanto a abordagens e objetivos de aprendizagem - os cursos de extensão e de pós-graduação no Brasil buscam suprir essa demanda. Recentemente, em Fortaleza, a UNI7 (Universidade 7 de setembro) deu início a primeira especialização em educação bilíngue e bilinguismo do Ceará.

Assim, evidenciado o amadurecimento das propostas de ensino de língua inglesa na escola, mesmo tendo em contrapartida as questões referentes à legislação, avaliamos como extremamente positivo, para os alunos primordialmente, e, consequentemente para o professor. Vislumbramos um desenvolvimento na educação para comunidades mais globalizadas onde a interação potencializa o apagamento de fronteiras (ROJO, 2013) e a troca de conhecimento ocorre com maior fluidez. Para que essas propostas ganhassem corpo, diversas condições foram atendidas. Primeiramente, a ampliação da carga horária e a organização dos planejamentos de aula a partir de competências e habilidades, em seguida, o posicionamento do aluno no centro do processo de ensino. Ainda, o desenvolvimento da oralidade e da compreensão auditiva se igualam em status às habilidades de leitura e de escrita. Soma-se a habilidade de leitura multimodal, evidenciada nos documentos oficiais (BRASIL, 2018) e presente em nossa sociedade. São mudanças significativas para os professores, que, nesse ínterim, remodelam suas práticas e buscam se adaptar ao contexto.

Quanto às competências do professor bilíngue, é preciso que este domine muito além da língua para ter êxito em sua prática escolar. É necessário que conheça as fases do desenvolvimento infantil e tenha estratégias de ensino para alcançar seu público-alvo, tornando o ensino da língua contextualizado e adequado às distintas realidades e interesses da comunidade. Segundo Megale (2014), os professores deveriam dominar múltiplos saberes, de modo a atender à demanda do contexto diversificado que temos no Brasil. A autora elenca algumas competências imprescindíveis a esses professores, das quais destacamos:

[...] conhecimento sobre os processos e fatores envolvidos no biletramento; conhecimento linguístico e semântico das línguas ensinadas no contexto educacional bilíngue; conhecimento acerca das teorias de aquisição de primeira e segunda língua; valorização da pluralidade cultural; conhecimento de teorias e modelos 
educacionais bilíngues; domínio das diversas áreas de conhecimento, como matemática, ciências e artes [...]. (MEGALE, p. 3, 2014).

Para a autora, é necessário que o professor tenha conhecimento em diversas áreas, como psicolinguística, sociolinguística e psicopedagogia. Enfim, o professor de inglês dos programas bilíngues, precisa ser um profissional multifacetado. Ainda, acreditamos que os saberes do professor de inglês devem abranger aspectos práticos da rotina das escolas. A educação básica, envolve muitas atividades extraclasses como, por exemplo, eventos, projetos, aula de campo, apresentações, comemorações cívicas e religiosas, feiras de ciências e amostras de arte. Com a frequência maior do professor de inglês na escola, resultado do acréscimo de carga horária, a participação dele em todas essas atividades torna-se natural e esperada. Assim, observamos a aprendizagem da língua estrangeira, ou língua adicional, ultrapassando as paredes das salas de aula e buscando os outros espaços da escola. O professor de inglês precisa penetrar nesse mundo, trabalhar em parceria com outros professores, de forma interdisciplinar ou mesmo transdisciplinar.

\section{Metodologia}

A pesquisa em Linguística Aplicada tem como aspecto basilar compreender a realidade, não se limitando a resolver problemas (PAIVA, 2019). A presente investigação enquadra-se na modalidade aplicada, pois além de gerar novos conhecimentos busca desenvolver novas formas de pensar a prática e a formação de professores a partir de informações e relatos de experiências desses profissionais. Essa seção se divide em três subseções: a primeira apresenta a contextualização da pesquisa, em seguida a descrição dos participantes, e finalmente, as análises dos resultados.

\section{Contexto da pesquisa}

Gláuks: Revista de Letras e Artes-jan/jun. 2020 - Vol. 20, $N^{o} 1$ 
Percebemos, a partir de acesso à anúncios de emprego ${ }^{4}$ postados nas redes sociais e à quadros de avisos de universidades e faculdades públicas e particulares da região metropolitana da cidade de Fortaleza, que escolas particulares buscam professores fluentes e certificados por sua competência linguística, graduados em Pedagogia ou em Letras. Mais um aspecto característico está na carga de trabalho desses professores, que pode chegar a mais de trinta horas semanais. Há escolas que passaram de uma aula de inglês semanal para cada turma para cinco aulas semanais. A relação do professor com os alunos se torna mais estreita e o status da disciplina de língua inglesa se equipara às demais disciplinas da escola.

Como mencionado anteriormente, a cidade de Fortaleza conta apenas com uma escola bilíngue, que trabalha com os currículos brasileiro e canadense. No entanto, observamos um número significativo de escolas particulares regulares (monolíngues) que implantaram programas bilíngues a partir de 2016. Nessas escolas a língua adicional é um diferencial na formação de crianças e jovens; esses programas bilíngues propõem um modelo de ensino de língua inglesa adaptado às escolas cearenses com as seguintes características: i) atendendo expectativas dos pais, as aulas são inseridas na carga horária diária dos alunos; ii) abordagem de ensino de língua estrangeira baseada em desenvolvimento de habilidades e competências (habilidades para os alunos do século 21), abordagens investigativas, abordagem comunicativa, método direto (aquisição de língua estrangeira), CLIL - abordagem integrada para o desenvolvimento de competências linguísticas e de conteúdo. Trabalha-se com estratégias de ensino que colocam o aluno como protagonista do percurso de aprendizagem ou de investigação e projetos e propostas multidisciplinares; iii) carga horária estendida. As escolas onde trabalham os professores que responderam a essa pesquisa, são escolas regulares com programas bilíngues, apresentam currículo brasileiro apenas, com um programa robusto de aulas de inglês. Devido ao incremento de carga horária, os alunos contam com exposição maior à língua, professores trabalham com abordagens que incentivam a pesquisa e o

4 Pesquisamos anúncios postados no instagram e facebook. Também, acessamos mensagens trocadas em grupos de professores no whatsapp. Consideramos anúncios de emprego em quadros de avisos de universidades e faculdades públicas e privadas. Observação foi realizada no periodo de 20/07/2019 à 20/11/2019 foram contabilizados anúncios de 38 escolas buscando professores de educação infantil, fundamental 1 e 2 e ensino médio. Não contabilizamos anúncios de cursos de idiomas e de empresas de recrutamento. Escolas da região metropolitana da cidade de Fortaleza. 


\title{
GLÁUKS
}

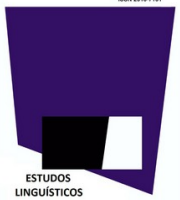

protagonismo do aluno, como especificado acima, além de conteúdos acadêmicos nas áreas de cultura, matemática e ciências, principalmente.

Esse crescimento do ensino de inglês nas escolas de Fortaleza ocorre devido às condições financeiras favoráveis dos alunos que podem frequentar essas escolas e de seus pais que desejam que seus filhos tenham uma formação que inclua uma língua estrangeira, preferencialmente inglês, que assume um papel de língua mundial. Rajagopalan (2005) estima que $1 / 4$ da população tem algum nível de proficiência em inglês e que mais de $80 \%$ da produção acadêmica é em inglês, então essas escolas estão absolutamente coerentes em dar esse espaço à aprendizagem desse idioma. Essas escolas apresentam status valorizado por oferecerem programas bilíngues e seus professores devem atender às expectativas desse público, que é exigente, porém com pouco domínio do idioma. Os alunos têm acesso à internet e ao mundo globalizado, frequentam a escola regularmente, têm boas condições de estudo, podemos dizer que até posição privilegiada se comparamos à totalidade de escolas do estado. Portanto, nessas condições, podemos inferir que esses alunos atingirão algum nível de proficiência da língua adicional.

O objetivo do presente estudo foi entender se as mudanças identificadas no cenário de ensino de língua inglesa nas escolas particulares de Fortaleza se traduzem como vantajosas para os professores Para tanto, foram analisados questionários respondidos anonimamente por 29 professores de inglês que trabalham em programas bilíngues de escolas particulares na cidade de Fortaleza, a fim de responder às seguintes perguntas de pesquisa: (i) como os professores percebem a chegada dos programas bilíngues nas escolas particulares de Fortaleza? (ii) Quais saberes os professores de inglês de programas bilíngues devem mobilizar para realizar seu trabalho? (iii) Os professores percebem os programas bilíngues como vantajosos para eles nos aspectos profissionais?

\section{Participantes da pesquisa e instrumento para construção de corpus}

\author{
Gláuks: Revista de Letras e Artes-jan/jun. 2020 - Vol. 20, $N^{o} 1$
}


Nessa seção desenvolvemos um desenho do perfil do professor de inglês dos programas bilíngues das escolas particulares na cidade de Fortaleza a partir do corpus coletado. Para esse estudo participaram 29 professores de inglês, voluntários, os quais leram e concordaram com um Termo de Consentimento Livre e Esclarecido antes de responderem ao questionário da pesquisa ${ }^{5}$. $\mathrm{O}$ instrumento utilizado consistiu em um questionário disponibilizado em formulário da plataforma Google, contendo 23 questões, distribuídas em 3 seções: (i) Informações gerais; (ii) Informações sobre a formação do professor de inglês; (iii) Informações sobre a prática do professor de inglês. Os participantes responderam ao questionário online, anonimamente, no período de 05 a 25 de outubro de 2019. As informações sobre o perfil desses professores podem ser visualizadas na Tabela 1 .

Tabela 1. Perfil dos participantes.

\begin{tabular}{|l|l|l|l|l|}
\hline \multicolumn{2}{|l|}{ SEXO } & \multicolumn{4}{l|}{ FORMAÇÃO } \\
\hline Masculino & Feminino & Graduandos & Graduados & Pós-graduados \\
\hline $27,6 \%$ & $72,4 \%$ & $24,1 \%$ & $75,9 \%$ & $20,7 \%$ \\
\hline NATURALIDADE & EXPERIÊNCIA DOCENTE \\
\hline Ceará & Outros estados & Até 1 ano & De 1 à 4 anos & Mais de 5 anos \\
\hline $82,7 \%$ & $17,2 \%$ & $13,8 \%$ & $37,9 \%$ & $48,3 \%$ \\
\hline
\end{tabular}

Fonte: As autoras.

Frente às respostas obtidas a partir dos questionários, destacamos dois aspectos acerca do perfil dos participantes. Primeiramente, ressaltamos que 82,7\%, dos 29 participantes da pesquisa, são naturais do estado do Ceará. Então, nossas análises mostram um retrato regional do professor que se engaja no ensino de inglês das escolas particulares de Fortaleza. Um segundo aspecto, temos um grupo de profissionais majoritariamente feminino, $72,4 \%$. Como os programas bilíngues nas escolas de Fortaleza ainda atingem, em sua maioria, a educação infantil e ensino fundamental, esse resultado reforça o perfil de professora cuidadora, segundo Rocha (2012), representa para as professoras a perda de identidade profissional a partir de raízes históricas da formação do professor. Enfim, evidencia o fato de a sociedade ainda atribuir à mulher a responsabilidade pelos cuidados com as crianças.

5 O estudo foi previamente aprovado pelo Comitê de Ética em Pesquisa da Universidade Federal do Ceará.

Gláuks: Revista de Letras e Artes-jan/jun. 2020 - Vol. 20, $N^{o} 1$ 
Nossos resultados trouxeram uma amostragem de professores experientes bem representativa, 48,3\%. Falamos de professores com mais de cinco anos de experiência. Com esse dado, validamos nossa questão de pesquisa sobre os saberes que os professores ${ }^{6}$ de programas bilíngues devem mobilizar para realizar seu trabalho. Ficam claras as adaptações e reformulações que o professor precisa implementar à sua prática já consolidada por serem professores experientes.

\section{Análise e discussão dos dados}

Nesta seção apresentamos os principais dados coletados a partir das respostas dos 29 professores de inglês ao questionário da nossa pesquisa. Ao longo desta seção apresentaremos excertos das respostas dos professores, os quais apresentaram temáticas essenciais para a discussão e análise da prática dos professores de inglês dos programas bilíngues das escolas particulares de Fortaleza. O primeiro dado relevante a ser abordado nesta seção diz respeito ao segmento em que os 29 professores participantes da pesquisa atuam. As respostas dos participantes podem ser visualizadas no Gráfico 1.

Gráfico 1. Segmento de ensino

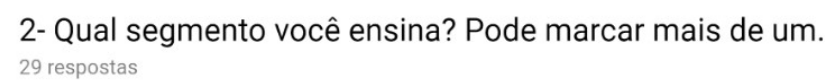

29 respostas

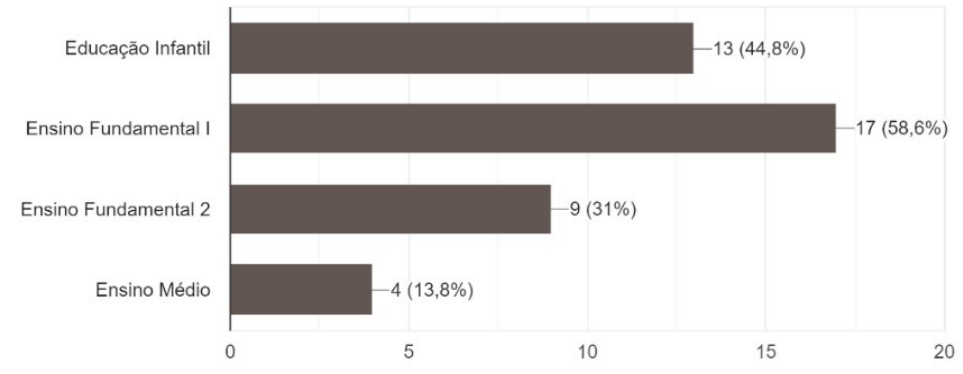

Fonte: As autoras.

6 Os professores foram formados em cursos de idiomas, geralmente com abordagem comunicativa, ou em escolas regulares, com abordagem tradicional com foco na leitura e escrita.

Gláuks: Revista de Letras e Artes-jan/jun. 2020 -Vol. 20, $N^{o} 1$ 
O Gráfico 1 demostra a distribuição dos professores por segmento de ensino, cabe destacar que um professor pode atuar em mais de um segmento. Podemos observar que a menor porcentagem de professores de inglês está no Ensino Médio, isso ocorre pois os programas bilíngues iniciaram na educação infantil e ensino fundamental avançando para o ensino médio, gradualmente.

No que tange a carga horária dos programas, os dados do presente estudo mostraram que quase $80 \%$ dos participantes trabalham em escolas que oferecem quatro ou cinco aulas de inglês semanalmente aos alunos, o que representa significativo aumento na carga horária do professor já que a carga horária de inglês costumava ser de uma aula semanal. Gostaríamos de destacar que esse fator é muito importante e que, no Brasil uma pequena porcentagem de escolas tem essa oferta de aulas semanais. O British Council realizou em 2015 uma pesquisa intitulada "O Ensino de Inglês na Educação Pública Brasileira/British Council/Plano CDE" que demonstrou que apenas 5\% das escolas estaduais e $8 \%$ das municipais tem quatro ou mais aulas de inglês semanais. Acrescentamos essa informação, mesmo que em comparativo com a escola pública brasileira, para evidenciar que as escolas particulares em Fortaleza estão, de fato, investindo em uma carga horária que exerça uma diferença na exposição dos alunos a língua inglesa. Ainda, acreditamos que esse aspecto representa um enorme impacto na atividade dos professores em diversos aspectos, principalmente no financeiro e na mobilização de saberes (formação).

Trabalhando ainda com os dados que evidenciam o perfil desse professor e sua formação, observamos que $62 \%$ tem formação em Letras. Esse percentual é superior às médias nacionais apontadas pelo Censo da Educação Básica 2017 para os professores de inglês com licenciatura na área de atuação. O censo revela que apenas $42 \%$ dos professores de ensino fundamental e 56\% dos professores de ensino médio têm licenciatura ou bacharelado com fundamentação pedagógica. Outro fator que revela investimento desse profissional em sua formação é que $20 \%$ dos professores que responderam aos questionários, além de graduados, têm especialização na área de ensino e aprendizagem de língua estrangeira. $\mathrm{O}$ 
percentual de professores pós-graduados ainda é baixo se comparado com os padrões nacionais, mas é um indicativo de professores mais preparados e mais engajados na profissão.

O Anuário de Educação Básica 2017 é um documento oficial onde estão especificados, entre outros objetivos para a educação brasileira, aqueles para a formação de professores. Formar, em nível de pós-graduação, 50\% dos professores, até o último ano de vigência deste PNE (2024) é o objetivo traçado para a educação básica. Para os professores de inglês dos programas em questão, é um ponto de melhoria, já que o nosso estudo sobre a formação dos professores de inglês aponta para as especializações como uma forma de preencher a lacuna deixada pela graduação.

Conforme expusemos em outras seções deste estudo, as mudanças de abordagem e o incremento de carga horária, entre outros aspectos, apontam diferenças na prática de professores de programas bilíngues. A seguir apresentamos 5 respostas para a questão: "Você percebe diferenças no perfil dos professores de inglês que atuam hoje nas escolas privadas com programas bilíngues quando comparados aos professores que atuam em escolas com propostas mais tradicionais de ensino de língua estrangeira? Quais diferenças destacaria?”

\footnotetext{
P02- Os professores de programas bilíngue buscam ser bem mais dinâmicos e estão sempre procurando formas novas de trabalhar com o conteúdo!

P04- O nível linguístico dos professores dos programas bilíngues é maior. Muitos tem certificado de proficiência e/ou experiência no exterior.

P06- Geralmente, professores de escola bilíngue possuem formação na área, e não apenas sabem a língua.

P08- Sim. A maior diferença do bilíngue é a aula ser $100 \%$ em inglês, isso já modifica todo o comportamento e contato do aluno diante da língua estrangeira. Ao contrário das propostas mais tradicionais, o bilíngue utiliza menos o quadro e aborda atividades práticas com maior participação dos alunos.

P15- Sim. Os professores de programas bilíngues são (sic) mais dinâmicos.

P20- A abordagem tradicional é geralmente baseada na gramática, mesmo quando parte dos gêneros. Os programas bilíngues têm geralmente abordagem comunicativa, buscando a vivência da língua de maneira mais integral e com consciência dos aspectos culturais.

P24 Sim. São mais jovens e dinâmicos.
}

Os comentários dos professores são certamente calcados não apenas em suas experiências profissionais, mas também em suas crenças e em suas vivências (sua vida escolar). Convém destacarmos que tais excertos revelam que os professores compartilham 
uma visão positiva de sua prática, palavras assertivas são citadas como referência às práticas dos professores dos programas bilíngues como: atitude, liberdade e dinamismo. Ao responder a esta pergunta eles experimentaram um exercício de olhar para a sua prática de uma posição "exotópica" (excedente de visão), conceito bakhtiniano que considera "dimensões extralinguísticas" (BRAIT, 2006, p.12), como tempo e lugar. O professor, ao identificar características do perfil dos professores de inglês que atuam hoje nos programas bilíngues de escolas privadas, descreveram, na verdade, a própria prática.

Outros aspectos analisados neste estudo diziam respeito ao suporte de uma gestão pedagógica e sobre a formação continuada. Para analisar essas questões, pedimos aos professores que reagissem com "sim" ou "não" à algumas afirmativas sobre suas atividades profissionais. Em seguida, pedimos que acrescentassem um comentário, espontaneamente. A seguir apresentamos 2 desses comentários.

\footnotetext{
Você gostaria de registrar alguma observação sobre as afirmações na questão 9? Se sim, utilize as linhas abaixo para suas observações.

P16 - Acredito que se uma escola se propões a ter um programa bilíngue, se faz indispensável um acompanhamento da coordenação e de formações acerca do tema. P21 - Como qualquer profissional autocrítico, reconheço que tenho segurança em vários aspectos, porém sei que há conceitos e habilidades ainda a serem desenvolvidos (e sempre haverá esse espaço para crescimento), dada a dinâmica do ensino e da aprendizagem na idade escolar.
}

Tratando-se da reação dos professores ao item sobre o suporte de uma gestão de língua inglesa na escola, aproximadamente $90 \%$ afirmam contar com o suporte de um coordenador ou supervisor de área, esse dado revela investimento e preocupação das escolas quanto ao ensino e aprendizagem de língua estrangeira, há pouco tempo não havia coordenadores bilíngues nas escolas de ensino básico. O coordenador, ao se colocar como agente motivador de sua equipe e assegurar que as boas ideias tenham continuidade liga e interliga pessoas, e consequentemente, amplia o espaço de aprendizagem do professor (LIBÂNEO, 2013). Além do que se passa dentro das quatro paredes da sala de aula, há muito mais a aprender no convívio do coletivo. É preciso lembrar que quem não está em classe, imerso naquela realidade, pode ser capaz de estranhar. É do estranhamento que surgem bons problemas, o que é muito mais importante do que quando as respostas aparecem prontas. Só assim é possível 


\section{GLÁUKS}

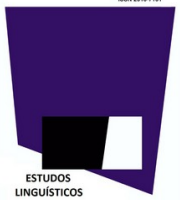

que o coordenador efetivamente forme professores (e esse é o seu papel primordial). Segundo Nóvoa (2001), a experiência não é nem formadora nem produtora. É a reflexão sobre a experiência que pode provocar a produção do saber e a formação". Ainda, nos comentários espontâneos, que apresentamos no excerto anterior, percebemos a postura reflexiva dos professores quanto aos desafios do programa bilíngue. Os resultados desse estudo sugerem que os professores passam por formação continuada; $82 \%$ dos professores afirmam que passaram por formação no trabalho. No entanto, $30 \%$ ainda sentem falta de formação continuada.

Os participantes também foram questionados sobre as abordagens/métodos utilizados nos seus locais de trabalho. São apresentadas 3 respostas a seguir.

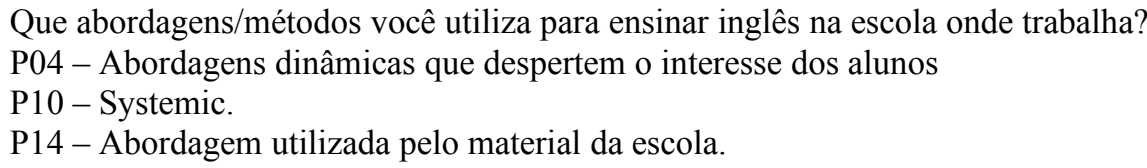

Consideramos o excerto apresentado extremamente significativo para nosso estudo, pois a partir das respostas dos professores ao questionamento sobre as abordagens/métodos utilizados por eles para ensinar inglês nos chama atenção as respostas de alguns professores que não filiam suas abordagens aos conceitos divulgados na academia e, possivelmente, ao apontar "abordagens dinâmicas" (excerto P04) esse participante pode estar se referindo a gamificação ou uso de tecnologia em sala de aula de maneira não sistematizada. Ainda sobre as abordagens pedagógicas utilizadas pelos professores, os resultados consolidados revelam que $10 \%$ dos professores trabalham com CLIL, $3 \%$ cita as metodologias ativas, sala de aula invertida e UBD - Understanding by design. Além disso, 20\% dos professores cita a abordagem comunicativa, $17 \%$ o Communicative Language Teaching - CLT que é um método proposto por Halliday em 1970. Identificamos nas abordagens uma esfera complexa e que exige dedicação e investimento do professor.

Consideramos importante acrescentar a esta análise os resultados apurados sobre a competência linguística dos professores. $48 \%$ dos professores afirmam ter aprendido inglês em cursos de idiomas, $13,7 \%$ se consideram autodidatas e apenas $7 \%$ fazem menção a estudos 
no exterior. Esses números reforçam que não se aprende inglês na escola básica brasileira, nenhum professor dos que responderam o questionário, apontou a escola básica como preponderante no seu aprendizado de inglês. Os programas bilíngues têm o potencial para reverter esses dados, acreditamos que as crianças e jovens que hoje estão nos programas bilíngues, atingirão um nível de domínio da língua adicional. No tocante, não podemos deixar de mencionar, que a maioria das escolas com programas bilíngues são caracterizadas como de elite, e apenas uma porcentagem muito baixa de crianças e jovens brasileiros estão engajados em escolas com as características descritas nesse estudo.

Ainda sobre o aspecto da competência linguística desses professores, cabe mencionar que $65 \%$ dos participantes afirmaram ter algum tipo certificado de proficiência ${ }^{7}$ em língua inglesa. A busca dessa certificação nos mostra o engajamento dos professores em atingirem níveis mais altos de qualificação técnica para a realização de sua atividade profissional, além de alavancar melhor remuneração proporcionam mais autoregulação e autoestima.

Para investigar a opinião dos professores entrevistados sobre o papel da formação na atuação profissional, perguntamos: "Em que aspectos sua formação acadêmica contribui para que você seja um bom professor nos programas de inglês dentro de escolas particulares na cidade de Fortaleza?” Algumas das respostas são apresentadas a seguir.

\begin{abstract}
Em que aspectos sua formação acadêmica contribui para que você seja um bom professor nos programas de inglês dentro de escolas particulares na cidade de Fortaleza?

P01 - Aprendi muito sobre a língua, sobre educação em geral, mas também em considerações e reflexões que temos que ter diante dos nossos alunos.

P02 - Ainda estou cursando Letras. Mas contribui por me oferecer oportunidades que com minha primeira formação eu não teria.

P04 -Além da língua em si, no conhecimento necessário para trabalhar os assuntos abordados e no planejamento das aulas.

P14 - Honestamente, no modelo atual de ensino bilíngue a formação pouco importa pois é uma tarefa quase que impossível.

P16 - Creio que apenas na questão do conhecimento da língua e da cultura.

P20 - Fiz bacharelado, minha formação acadêmica foi baseada na área de tradução. Então, apesar de ter sido um curso excelente, não ajudou em nada na prática de sala de aula. Nesse aspecto, penso que um curso de pedagogia né teria sido mais útil.
\end{abstract}

7 A certificação internacional ganha espaço nos anúncios de seleção de professores de inglês como um diferencial, as escolas têm grande interesse em propor a seus alunos que se submetam aos exames, a avaliação externa baliza o desempenho da escola. Torna-se essencial que professores tenham passado pela experiência e possam ser um bom modelo a ser seguido.

Gláuks: Revista de Letras e Artes-jan/jun. 2020 - Vol. 20, $N^{o} 1$ 


\section{GLÁUKS}

Observamos no excerto apresentado, que os participantes têm opiniões divergentes sobre a contribuição de sua formação acadêmica para a prática nos programas bilíngues. Não nos surpreendemos com esse resultado. Enfim, explanamos nesse estudo, que a formação do professor para programas bilíngues, e para a educação bilíngue é um assunto em pauta e as universidades e faculdades ainda, timidamente, lançam-se com propostas de pós-graduação na área.

Então, temos em nosso corpus um número maior de profissionais formados em letras $62 \%$ e $24 \%$ de professores cursando ainda a graduação. Poucos pedagogos, e alguns que migraram de áreas como psicologia, administração e comércio exterior. Como podemos perceber, uma amostra bem diversificada e ao mesmo tempo fiel às características desse coletivo de professores que anseiam por formação continuada, que acolhem novos aprendizados e estão próximos aos centros de formação (buscando cursos de especialização e exames de proficiência). Encontram conceitos, abordagens e metodologias novas, diferentes daquelas que vivenciaram enquanto alunos, fato que pode se traduzir em adaptação ou conflito ou reflexão.

Assim, concluímos com a certeza que as escolas mostram que se adaptam aos programas bilíngues, mas os professores ainda precisam de mais suporte e formação, $30 \%$ dos participantes relatam sentir falta de formação no local de trabalho, e percebemos que os professores depositam grande confiança nessas oportunidades de formação em serviço para complementar seus estudos na graduação universitária ou para auxiliá-los na migração de outras áreas e para, principalmente, os aproximarem da rotina escolar e das especificidades dos programas bilíngues e suas abordagens para o ensino de língua inglesa.

\section{Considerações finais}

Nos últimos quatro anos observamos, nas escolas particulares na cidade de Fortaleza, mudanças diversas, principalmente nas abordagens de ensino de língua inglesa e na carga 
horária de trabalho dos professores. Observamos ainda, colossal procura das escolas particulares por professores de inglês, e o perfil almejado se tornou bem rigoroso, fatores esses que nos motivaram a realizar essa pesquisa sobre os professores de inglês dos programas bilíngues.

Neste trabalho nos propusemos, primeiramente, lançar luz às questões sobre bilinguismo e multilinguismo para destacarmos que pouco se discute sobre esse assunto no Brasil e que muitos, equivocadamente, consideram o Brasil uma nação monolíngue e desconhecem os impactos desse logro para as escolas brasileiras e para a formação de professores bilíngues no Brasil. A seguir, discorremos sobre a formação dos professores de inglês no Brasil, assim trouxemos questões de legislação de escolas bilíngues e a carência de cursos de graduação que contemplem essa modalidade de ensino. Nosso objetivo foi entender se as mudanças identificadas no cenário de ensino de língua inglesa nas escolas particulares de Fortaleza se traduzem como vantajosas para os professores.

A análise dos questionários nos mostrou que os professores entrevistados percebem uma valorização de seu trabalho com a chegada dos programas bilíngues, mais horas dentro de sala de aula, mais estreiteza com o ambiente escolar, mais engajamento na escola e mais motivação a aprimorar seu nível linguístico e a buscar pós-graduações. No entanto, os professores revelaram inexperiência para a implementação de práticas docentes que promovam um olhar crítico acerca da língua inglesa no contexto escolar, carência de formação continuada e conflito da formação inicial com a prática.

Os professores têm se apropriado de novos saberes e começam a escrever uma história de sucesso. Revelaram, nesse estudo, satisfação, alegria e positividade ao olhar para sua profissão e sua prática. Também revelaram preocupação com a formação, o que indica reflexão sobre essa prática. É indubitável que o professor de inglês das escolas particulares tem mais oportunidade de trabalho, mais horas ativas por dia, e este fato é positivamente impactante na vida financeira dele. No entanto, mais responsabilidades acompanham o processo como a adaptação ao ambiente escolar (diferente de cursos de idiomas em vários aspectos) e as exigências das famílias e instituições; nível linguístico melhor; graduação na

\section{Gláuks: Revista de Letras e Artes-jan/jun. 2020 - Vol. 20, $N^{o} 1$}


área (que nem sempre foi exigida em anos anteriores), participação em reuniões de pais, são procurados e questionados sobre o aprendizado das crianças. Os programas bilíngues deverão elevar o nível de proficiência de inglês nas escolas e lançam os professores a novos desafios.

A universidade continua sendo a grande referência dos professores. As escolas exigem graduação na área; a formação no local de trabalho é valorizada, os professores buscam cursos de pós-graduação e o coletivo de professores se torna mais representativo nas escolas regulares, apostamos que poderão formar uma sólida rede de aprendizagem. Destacamos ainda, o aparelhamento das escolas para receber esses profissionais e garantir o sucesso dos programas bilíngues nas escolas particulares da cidade de Fortaleza.

Concluímos esse estudo na certeza de que essa discussão não se encerra aqui. A complexidade da atividade docente e os desafios encontrados por professores é campo fértil para investigações que venham a se somar às nossas e que possam contribuir com a comunidade acadêmica e com a atividade dos professores. Alegra-nos poder dar uma pequena contribuição para os estudos sobre a atividade de professores, sobretudo, para a atividade de professores de inglês de programas bilíngues que representam um número pequeno de profissionais, frente a escola pública estadual e municipal da cidade, no entanto, representam muito para cada um de seus jovens alunos.

\section{Referências bibiliográficas}

ALMEIDA FILHO, J. C. P. "O fazer atual da linguística aplicada no Brasil: Foco no ensino de línguas”. In: KLEIMAN, A.; COUTO CAVALCANTI, M. (eds.), Linguística Aplicada: suas faces e interfaces. Campinas: Mercado das Letras, 2007, p. 115-124.

BAKHTIN, M.; (VOLOCHÍNOV, V. N.) Marxismo e Filosofia da Linguagem: Problemas Fundamentais do Método Sociológico na Ciência da Linguagem. Tradução de Michel Lahud e Yara Frateschi Vieira. 16. ed. São Paulo: Hucitec, 2014.

BARCELOS A. M. F. "Lugares (im)possíveis de se aprender inglês no Brasil: crenças sobre aprendizagem de inglês em uma narrativa". In: LIMA D. C. (org.) Inglês em escolas públicas não funciona: uma questão, múltiplos olhares. São Paulo, Parábola, 2011, p. 147-158. 
BLOOMFIELD, L. Linguistic aspects of science. Philosophy of Science, v. 2, n.4, p. 499517,1935 .

BRAIT, B. "Análise e teoria do discurso". In: BRAIT, B. (Org.). Bakhtin - outros conceitoschave. São Paulo: Contexto, 2006.

BRASIL. Parâmetros Curriculares Nacionais: terceiro e quarto ciclos do ensino fundamental - língua estrangeira. Brasília, MEC, SEF, 1998,174 p.

BRASIL. Ministério da Educação. Governo Federal. Base Nacional Comum Curricular: BNCC-APRESENTAÇÃO,2018. Disponível em: <http:// http://basenacionalcomum.mec.gov.br/\#/site/inicio> Acesso em: 01 ago. 2018.

CAVALCANTI, M. C. Estudos sobre educação bilíngue e escolarização em contextos de minorias linguísticas no Brasil. D.E.L.T.A, v.15, p.385-417, 1999.

GARCÍA, O. Bilingual education in the 21st century: A global perspective. Oxford, WileyBlackwell, 2009, 481p.

GARCIA O.; JOHNSON, S. I.; SELTZER K. S. The translanguaging classroom: leveraging student bilingualism for learning. Language and Education, v.31, n.6, p. 590-594, 2017.

GROSJEAN. F. Life with two languages: an introduction to bilingualism. Cambridge, Mass, Harvard University Press, 1982, 370p.

LIBÂNEO J. C. Organização e gestão da escola: teoria e prática. $6^{\mathrm{a}}$ ed. Editora Heccus. 2013.

MAHER, T. M. "Formação de Professores Indígenas: uma discussão introdutória". In: GRUPIONI, L.D.B. (ed.). Formação de Professores Indígenas: repensando trajetórias. Brasília, MEC/SECAD, 2006, p. 11-38.

MARCELINO, M. Bilinguismo no Brasil: significado e expectativas. Revista Intercâmbio, v. 19, p. 1-22, 2009.

MEGALE, Antonieta. H. Bilinguismo e educação bilíngue - discutindo conceitos. Revista Virtual de Estudos da Linguagem. ReVEl, v.3, n. 5, p. 1-13, 2005.

MEGALE, A. H. A. Formação de Professores para a Educação Infantil Bilíngue. Pátio Educação Infantil, v.39, p. 12-15, 2014. 
MEGALE, A.; LIBERALI, F. Caminhos da educação bilíngue no Brasil: perspectivas da linguística aplicada. Raído, Dourados, v.10, n.23, p. 9-24, 2017.

NÓVOA A. Professor se forma na Escola. Nova Escola on-line, n. 142, Maio, 2001. https://novaescola.org.br/conteudo/179/entrevista-formacao-antonio-novoa\# Acesso em: 24 ago. 2020.

PAIVA. V.L. M. O. Manual de Pesquisa em Estudos Linguísticos. $1^{\mathrm{a}}$ ed. São Paulo, Parábola, 2019, p. 7 -30.

RAJAGOPALAN, K. "A geopolítica da língua inglesa e seus reflexos no Brasil: por uma política prudente e propositiva”. In: LACOSTE, Y.; RAJAGOPALAN, K. (eds.) $A$ Geopolítica do Inglês. São Paulo, Parábola, 2005, p. 135-159.

ROJO. R Escola conectada: multiletramentos e as TICS. 1ª ed. São Paulo, Parábola, 2013, p. 13-36.

ROCHA, L. Formação de Professor de Educação Infantil. Revista Projeção e Docência. n. 1, 2012. V.3. $28-36 . \quad$ Disponível em: $\mathrm{http} /$ /revista.faculdadeprojecao.edu.bt/index.php./Projecao3/article/view/171. Acesso em: 24 ago. 2020.

THIERY, C. "True bilingualism and second language learning". In: Language interpretation and communication. New York, Plenum Press, 1978, p. 145-153.

VALDES, G.; FIGUEROA, A. Bilingualism and testing: A special case of bias. Norwood, NJ, Ablex, 1994, 255 p.

\section{Challenges for english teachers of bilingual programs in private schools in Fortaleza}

Abstract: In the present study we discuss about bilingual programs teachers' in private schools in Fortaleza. Brazil find within this still so recent free of legislative scope. The objective of this study was to evaluate if the changes identified in the English language teaching scenario in private schools in Fortaleza are advantageous for teachers, therefore, anchored in the literature on bilingualism and multilingualism and teacher training, we seek to: a) Investigate the perception of teachers about the recent bilingual programs in private schools in Fortaleza; b) Identify knowledge teachers call up to carry out their work and, c) Assess whether teachers perceive bilingual programs as beneficial to them. In order to outline a profile of these teachers and collect data for our study, we applied a questionnaire to 29 


\section{GLÁUKS}

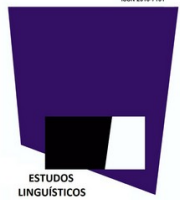

volunteer teachers. The analysis of the obtained responses showed that bilingual educators are being valued in the school context in Fortaleza, however, there is still a lack of continuing education. The present study hopes to contribute to the research in this newly, however, significant field of study.

Keywords: bilingual programs; teacher's education; bilingualism. 